\title{
Through the Looking Glass ... and What You May Find There
}

Janice Munroe

$\mathrm{H}_{\mathrm{t}}$ ave you ever thought about becoming more involved with the Canadian Society of Hospital Pharmacists (CSHP)? Perhaps an Executive Officer position is intriguing, but you aren't quite certain what it's all about.

In March 2012, the CSHP Nominating Committee recommended that a mentorship program be established to introduce Society members to the CSHP Executive Officer "experience" with "no strings attached". The program would introduce the Executive mentee to "life as an Executive Officer" through shadowing of the CSHP Past President or Director of Finance, participating in monthly Executive Committee teleconferences, learning about the operations of CSHP, and completing a project related to the mentor's portfolio.

CSHP Council endorsed the recommendation, and the first call for the position went out in May 2012. From among the several applicants who expressed interest, Mitsuyo Miyata from British Columbia was selected to become the first Executive mentee and was paired with me in my role as Past President and Internal Liaison.

Mits' term began at the 2012 Summer Educational Sessions (SES) in Charlottetown, PEI, where he was immediately immersed in a multitude of meetings, including meetings of the Executive Committee and Council, as well as our joint meetings with officers of other organizations. He also participated in the discussion of major issues affecting CSHP during Council's "Issues Day". In short, Mits quickly became integrated into CSHP's Executive-level operations.

At the conclusion of the Council meetings last summer, Mits was given a major assignment, with his appointment as Chair of the newly constituted SES Sustainability Task Force. The Task Force is responsible for evaluating the factors affecting the financial sustainability of the SES and for producing a formal report with recommendations to enhance the success of the SES and to sustain this flagship CSHP educational event well into the future.

It seems safe to say that the mentorship program has raised Mits' awareness and understanding of what CSHP is, what it stands for, and how it accomplishes its mission of advancing safe, effective medication use in hospitals and other collaborative health care settings. It has given him the opportunity to work with pharmacy leaders in actively shaping the future of the profession. Serving in the role of

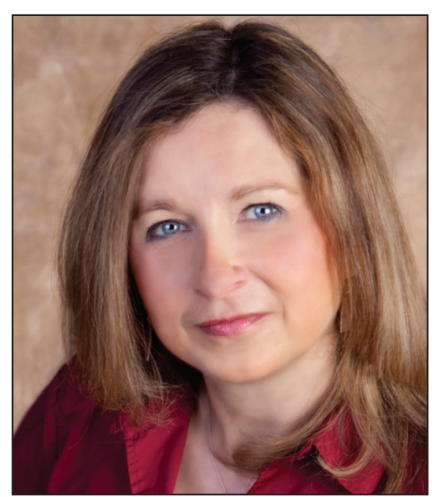
Executive mentee has helped to clarify for Mits what it means to be a CSHP Executive Officer. In essence, it has prepared him for a future Presidential Officer role, should he choose to take up such a position.

The CSHP Executive Mentorship Program has been a positive experience for Mits as the mentee, for CSHP as an organization (in particular through the recommendations being developed by the SES Task Force), and for myself as the inaugural Executive Officer mentor. I'd like to sincerely thank Mits for his active participation and commitment. He has made positive contributions that will benefit both CSHP as a whole and its members.

As the end of this inaugural mentorship approaches, the Nominating Committee will issue a call for applications for the coming year. In the 2013/2014 term, 2 mentorship opportunities will be available to CSHP members: one for the External portfolio and the other for the Finance portfolio. The CSHP Executive Mentorship Program is an excellent opportunity for you to peek "through the looking glass" . . you never know what you will find there!

Janice Munroe, BScPharm, is Past President and Internal Liaison for the Canadian Society of Hospital Pharmacists. 